\title{
A ORGANIZAÇÃO SOCIAL DOS ASSENTADOS DO VEREDA I: trajetórias singulares
}

\section{THE SOCIAL ORGANIZATION OF THE VEREDA I ASSESMENT: re- socialization and migration}

\section{LA ORGANIZACIÓN SOCIAL DE ES ASENTADOS DEL VEREDA I: trayectorias singulares}

\author{
Marcelo Leles Romarco de Oliveira \\ Departamento de Economia Rural da Universidade Federal de Viçosa. \\ Campus Universitário, 36570.000 - Viçosa - MG - Brasil. \\ E-mail: mlromarco@yahoo.com.br
}

\author{
José Roberto Pereira \\ Departamento de Administração e Economia da Universidade Federal de Lavras - UFLA. \\ Campus da UFLA. Caixa Postal 3037 - CEP 37200-000 - Lavras MG \\ E-mail jpereira@ufla.br
}

\section{Resumo}

Este trabalho procura analisar a organização social no assentamento Vereda I, localizado no município de Padre Bernardo, região do Entorno do Distrito Federal, Estado de Goiás. Procurando compreender as razões que levaram trabalhadores a migrarem do campo para as cidades, e depois para áreas de assentamentos. Nesse estudo de caso, utilizou-se da história oral e de entrevistas como técnicas para coleta das informações. Observou-se que, a falta de perspectiva em permanecer em seus locais de origem, aliada ao encantamento que a cidade exercia sobre eles, foram os principais fatores na decisão de migrar para Brasília. Porém, as condições de vida na cidade foram difíceis, pela falta de qualificação e trabalho. Resolvem, então, partir para assentamentos rurais e, neste espaço os migrantes reproduzem os valores comuns à origem e à suas trajetórias e como estratégia de superação de problemas encontrados por eles na cidade, tornando-se um novo lugar de organização social.

Palavras-chave: Organização Social; Migração; Trajetória de vida; Assentamentos Rurais.

\begin{abstract}
This work to analyze the social organizational in the Vereda I settlement, placed in Padre Bernardo, region called by Entorno of the Federal District, State of Goiás. The research had as objective to understand the reasons wish took these migrants workers from the country to the cities and afterwards to rural settlements, as well as the social organization about this process. In this study of case, it was used of verbal history as main technique for the collection of the information. It was observed that, in accordance
\end{abstract}


with the interviewed ones, the lack of perspective in remaining in its places of origin, added to the enchantment the cites had on them, mostly because of their relatives who migrated before and kept telling illusionary stories about the city life, these were the main points on wish they based the decision of moving to Brasília. However, the conditions of life in Brasilia had finished being difficult, mostly because of the lack of qualification of the migrants what made of them an excluded lawyer of the job worked, once the wouldn't fit the qualification requirements. Therefore, the settlement can be seen as a place of reproduction of common cultural values to the origin and as strategy of overcoming of problems found for them in the city, becoming the place of its organization and social reproduction.

Keywords: Social organization; Migration; Trajectory of life; Peasants; Rural Settlements.

\section{Resumen}

Este trabajo busca analizar la organización social en los asentamientos rurales de la región de la capital brasileña de Brasilia. Tratar de entender las razones por qué los trabajadores migran del campo a las ciudades y luego a las zonas de asentamiento. En este caso, se utilizó la historia oral y técnicas de entrevistas para recabar información. Se observó que la falta de perspectiva de quedarse en sus lugares de origen, junto con el encanto que la ciudad tenía sobre ellos, fueron los principales factores en la decisión de trasladarse a Brasilia. Sin embargo, las condiciones de vida eran difíciles de la ciudad, la falta de cualificación y el trabajo. Deciden ir a los asentamientos rurales, los migrantes en este espacio se reproducen los valores comunes a la fuente y su trayectoria y como una estrategia para superar los problemas encontrados por ellos en la ciudad, por lo que es el lugar de la organización social.

Palabras clave: Organización social, migración, trayectorias de la vida, los asentamientos rurales.

\section{Introdução}

Este trabalho se fundamenta nos resultados de uma pesquisa realizada entre os anos de 2001 a 2007, no assentamento Vereda I (constituído por 70 famílias de migrantes), localizado no município de Padre Bernardo-GO região do Entorno do Distrito Federal. Um dos objetivos da pesquisa foi analisar as razões que levaram trabalhadores rurais a migrarem do campo para as cidades, e depois para áreas de assentamentos rurais na região do Entorno do Distrito Federal (DF), focalizando, sobretudo, na organização social resultante desse processo.

O interesse em aprofundar os conhecimentos acerca da temática assentamentos rurais e migrações, surgiu a partir do envolvimento e a participação dos pesquisadores na elaboração do Plano de Desenvolvimento de Assentamentos (PDA) deste espaço. 
Entretanto, é importante ressaltar que o foco deste estudo não foi o processo migratório em si, mas o resultado que a migração proporcionou para a organização do assentamento Vereda I. Na região da pesquisa supracitada, os diversos assentamentos rurais existentes foram criados no final dos anos de 1990 e foram constituídos por trabalhadores de origem rural que migraram de várias regiões do Brasil para trabalhar, sobretudo, na prestação de serviços e na construção civil em Brasília, antes de chegarem ao assentamento. Depois de muitos anos ou até décadas morando na cidade, o grupo estudado acabou se envolvendo com o Movimento dos Trabalhadores Rurais Sem Terra (MST), fruto dos contatos nas cidades satélites do Distrito Federal, culminando assim na adesão da "luta pela terra", ou seja, entraram na luta para ocuparem terras e conseguirem terra para trabalhar.

Para Stédile e Gorgen (1993) uma das maneiras mais contundente de lutar pela terra é a ocupação desta, pois esse ato chama a atenção da imprensa, do governo e da sociedade. Dessa forma, o governo se sente pressionado a negociar as reivindicações dos trabalhadores sem-terra. Para estes mesmos autores, normalmente, as ocupações são feitas por um grande número de trabalhadores vindos de vários municípios diferentes e distantes, ocupando um latifúndio improdutivo ou terras de propriedade do governo.

Na região do Entorno do Distrito Federal, a luta pela terra não se deu de forma diferente, principalmente por causa da sua localização estratégica, da estrutura fundiária que beneficia os grandes especuladores de terras e da monocultura modernizada, associada à pecuária melhorada e o agronegócio, que beneficiam as grandes propriedades.

Estudos realizados por Aguiar et al. (1994) mostraram que a região do Entorno do Distrito Federal, sobretudo, nos municípios de Cristalina-GO e Padre Bernardo-GO possuem uma agricultura centrada na monocultura, o que têm causado sérios danos ao meio ambiente pelo uso excessivo de agrotóxico, pelo manejo inadequado dos recursos naturais e pela utilização de tecnologias poupadoras de mão de obra, esses elementos contribuíram para o deslocamento da população rural para a periferia das cidades satélites.

Além da questão fundiária e das transformações ocorridas no campo, Oliveira (2002) aponta que as cidades satélites do Distrito Federal passaram grande parte dos anos de 1990 com taxas muito elevadas de desemprego, tendo como destaque o ano de 
1998, em que a taxa de desemprego chegou à casa dos 19,50\%, maior taxa até então da década de 90.

Outro ponto que cabe destacar sobre o conflito de terras esta relacionado com processo de redemocratização do país que possibilitou um cenário político-social favorável à reforma agrária. E, a partir do final da década de 1990, o Movimento dos Trabalhadores Rurais Sem-Terras (MST) passou a ter também uma participação efetiva na luta pela terra nessa região. Desta forma, a concentração de terras e a proximidade com Brasília foram elementos que contribuíram para que a disputa por terras e a ocupação destas acontecesse nessa região.

Segundo Oliveira (2002), o aumento do número de ocupações de terras na região do DF e as pressões do MST 'forçaram' o antigo Ministério Extraordinário de Política Fundiária e o Instituto Nacional de Colonização e Reforma Agrária (INCRA) a criarem, em dezembro de 1997, a Superintendência Regional do Distrito Federal e Entorno SR (28). Com esse ato, o governo criou uma Superintendência com mais autonomia, com objetivo de amenizar a situação fundiária da região do Entorno do Distrito Federal.

Logo a Superintendência incorporou os municípios Goianos (Água Fria, Águas Lindas, Alexânia, Alvorada do Norte, Alto Paraíso, Buritinópolis, Cabeceiras, Campos Belos, Cavalcante, Cidade Ocidental, Cocalzinho, Colinas do Sul, Corumbá de Goiás, Cristalina, Damianápolis, Divinópolis de Goiás, Flores de Goiás, Formosa, Guarani de Goiás, Iaciára, Luziânia, Mambaí, Monte Alegre de Goiás, Mimoso de Goiás, Nova Roma, Padre Bernardo, Planaltina de Goiás, Posse, São Domingos, São João D'Aliança, Santo Antônio do Descoberto, Simolândia, Sítio da Abadia, Teresina de Goiás, Vila Boa e Valparaíso) e os municípios da região noroeste do estado de Minas Gerais (Arinos, Buritis, Formoso e Unaî), além do próprio Distrito Federal (BRASIL-INCRA, SEÇÃO 1, 30863, 23/12/1997).

Em Padre Bernardo, município no qual se dedicou a pesquisa supracitada, o marco dessa luta foi no ano de 1998, quando, iniciou as primeiras ocupações de terras. Os atores sociais que migraram para essas ocupações eram basicamente formados por famílias que depois de anos ou até décadas morando na cidade, sobretudo no Distrito Federal, descobriram o caminho para alcançar os seus objetivos, através da participação em movimentos populares, que buscam por meio das ocupações de terras um caminho 
para amenizar condições de fragilidades e mazelas que essas famílias, normalmente, se encontram.

A rigor, no município de Padre Bernardo-GO entre os anos de 1998 a 2008, foram criados oito assentamentos, com capacidade para assentar mais de 600 famílias. Desta forma, com a constituição destes assentamentos rurais ocorreu à possibilidade dos trabalhadores locais e os migrantes terem acesso a terra proporcionando a redistribuição da estrutura fundiária, o fortalecimento da produção familiar, além de possibilitar uma reorganização agrária no município. Entretanto, é importante ressaltar que a conquista desses espaços devem-se, sobretudo, pelas pressões exercidas pelos movimentos sociais de luta pela terra que corroboraram para que muitos trabalhadores que viviam na cidade voltassem ao campo.

Nesse sentido, a perspectiva de vida no assentamento pode possibilitar, por exemplo, acesso à infraestrutura e créditos, elementos importantes e necessários para que os assentados possam produzir e viver. Essa perspectiva só é possível porque esses trabalhadores estão determinados a melhorar suas condições de vida, apesar de ser um processo longo e desgastante, que envolve negociações constantes entre assentados e Governo, representado pelo INCRA. Na verdade, esses trabalhadores migrantes passam por processos de mudanças sociais que definem a direção de suas vidas e que, no caso em estudo, tem como ponto final, até então, os assentamentos rurais.

\section{Aspectos metodológicos}

A pesquisa teve como proposta norteadora descrever e analisar a trajetória de vida dos trabalhadores para o assentamento Vereda I e a organização social dos mesmos, desta forma procurou-se a conjugação de um conjunto de técnicas que permitisse uma maior interação e compreensão do problema a ser analisado. Para isso, foi elaborada uma estratégia de campo que permitisse através dos relatos orais e da observação participante compreender a trajetória de vida dessas famílias. Sendo importante destacar que as pesquisas de campo ocorreram entre os anos de 2001 a 2007.

Para a seleção dos entrevistados, que iriam contribuir para a formação da amostra foram traçados alguns critérios tais como:

1) Ter sua origem na zona rural: foram selecionados os assentados (a), de origem rural, ou seja, aqueles que foram socializados no meio rural; 
2) Ter migrado para a cidade e retornado para a zona rural, em áreas de assentamentos rurais: foram selecionados os assentados que moraram no espaço urbano por um período superior a 10 anos e que migraram para áreas de assentamento;

3) Ter trabalhado na cidade em atividades especificamente urbanas: o assentado deveria ter trabalhado em atividades que se caracterizam como empregos urbanos, por exemplo, funcionário público civil ou militar, construção civil, metalúrgico, prestador de serviços em geral, camelô, motorista, caminhoneiro, mecânico, dentre outros;

4) Não ser do estado de Goiás ou estados vizinhos: este critério, tinha por objetivo priorizar migrantes que se deslocaram de outros estados do Brasil para Brasília, privilegiando um deslocamento mais longo geograficamente.

Com os critérios definidos, foram selecionadas sete famílias de assentados para serem entrevistadas e, em seguida, foi elaborado um roteiro, para servir de orientação sobre o assunto, obedecendo a uma ordem cronológica das histórias dos migrantes, considerando seis fases na vida dos entrevistados, a saber: origem, decisão de migrar para a cidade, a vida na cidade, decisão de migrar da cidade para o acampamento, a vida no acampamento e no assentamento, e a vida futura. Assim os relatos orais foram fundamentais para a reconstrução da trajetória do grupo.

Destaca-se que o conceito de trajetória adotado nessa pesquisa vai além de um deslocamento geográfico, pois procuramos ressaltar acontecimentos vividos por migrantes que passaram por diversos processos de mudanças sociais até chegarem ao assentamento. Dessa forma, procurou-se analisar a trajetória dos assentados do Vereda I, considerando as posições sociais ocupadas por eles ao longo do tempo, passando de camponeses a trabalhadores assalariados na cidade, até chegarem ao assentamento, percorrendo uma longa trajetória até se tornarem assentados.

Além das entrevistas com as sete famílias selecionadas, outros assentados colaboraram com a reconstituição da história do acampamento e das dificuldades vividas por eles naquele período. Esse momento foi muito importante, pois contribuiu para resgatar a história referente à trajetória do próprio grupo, que ainda não havia encontrado oportunidade para isso.

Assim, os assentados do Vereda I mobilizaram todo o assentamento para organizar materiais visuais como foto, recorte de jornal, abaixo assinado, enfim, tudo que retratava a trajetória do grupo. 


\section{A vida no local de origem e a decisão de migrar para Brasília}

Os assentados entrevistados do Vereda I são de origem rural da região Nordeste do país e apresentam características sociais semelhantes, como pode ser observado na Figura 1 e no Quadro 1, respectivamente.

Quadro 1. Características sociais dos entrevistados

\begin{tabular}{|c|c|c|c|c|c|c|}
\hline $\begin{array}{l}\text { Entrevi } \\
\text { stados }\end{array}$ & $\begin{array}{c}\text { Ano de } \\
\text { migração }\end{array}$ & $\begin{array}{c}\text { Cidade de } \\
\text { origem }\end{array}$ & Idade $^{* * * *}$ & Escolaridade & $\begin{array}{c}\text { Primeira atividade } \\
\text { desempenhada no } \\
\text { DF }\end{array}$ & $\begin{array}{l}\text { Foi morar } \\
\text { com quem }\end{array}$ \\
\hline A & 1959 & Aquiraz (CE) & 20 & $1^{\mathrm{a}}$ série & Motorista em obras & Sozinho \\
\hline B & 1961 & Gilbués (PI) & 19 & $2^{\mathrm{a}}$ série & Servente & Com a irmã \\
\hline $\mathrm{C}$ & 1969 & Tutoia (MA) & 21 & $4^{\mathrm{a}}$ série & Apontador em obras & Com a irmã \\
\hline $\mathrm{D}^{*}$ & 1971 & $\begin{array}{r}\text { Novo-Exu } \\
\text { (PE) }\end{array}$ & 30 & $\begin{array}{r}\text { Sem } \\
\text { escolaridade }\end{array}$ & Mascate e faxineiro & Sozinho \\
\hline $\mathrm{E}$ & 1975 & $\begin{array}{r}\text { Umarizal } \\
(\mathrm{RN})\end{array}$ & 18 & $1^{\underline{0}}$ grau & Garçonete & Com o irmão \\
\hline $\mathrm{F}^{* *}$ & $1983 / 1985$ & $\begin{array}{r}\text { Pedreiras } \\
\text { (MA) }\end{array}$ & 19 & $6^{\underline{0}}$ serie & $\begin{array}{r}\text { Aprendiz de } \\
\text { mecânico }\end{array}$ & Com o irmão \\
\hline $\mathrm{G}^{* *}$ & $\begin{array}{c}1981 / 1984 / \\
1993\end{array}$ & Caxias (MA) & 17 & $4^{\mathrm{a}}$ série & Lanterneiro & $\begin{array}{r}\text { Com os } \\
\text { irmãos }\end{array}$ \\
\hline
\end{tabular}

Fonte: Oliveira, 2002

* Antes de ir para Brasília trabalhou em fazendas de café em GO em 1957; ** Entrevistados que migraram, retornaram para os locais de origem migrando para Brasília mais de uma vez; *** considerando a idade na época da primeira migração.
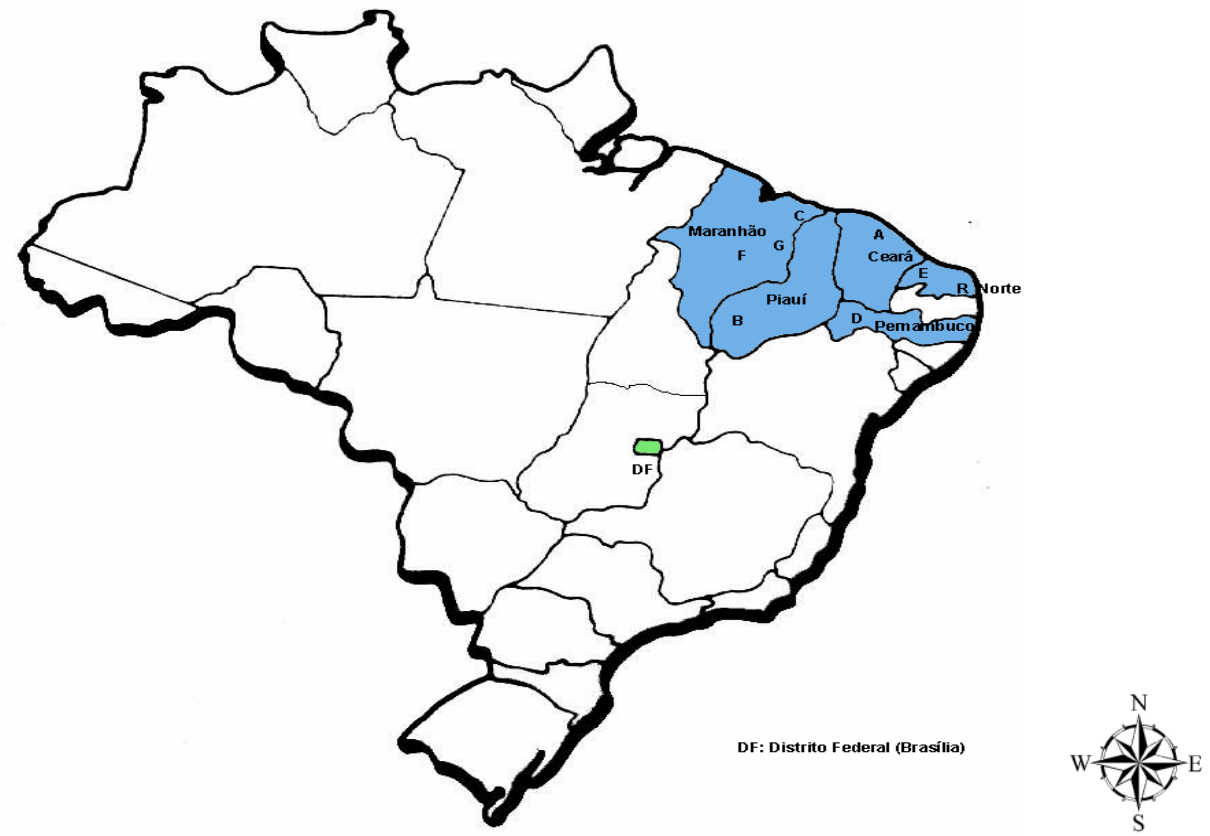

Figura 1. Estados de Origem dos entrevistados do assentamento Vereda I 
A organização do trabalho familiar dos migrantes em seus locais de origem estava centrada na estrutura patriarcal, em que o pai detinha os conhecimentos da produção e da comercialização, sendo o mesmo quem definia a realização das tarefas e a divisão do trabalho entre o grupo familiar. Nesta divisão, os membros da família seguiam a orientação de papéis diferenciados, sendo a roça o espaço dos homens e a casa o espaço das mulheres, incluindo o cuidado com as criações domésticas como cabritos, ovelhas, galinhas, entre outras, semelhante ao que foi observado por Woortmann's (1997) no livro “A lógica e a simbólica da lavoura camponesa”. Os relatos abaixo ilustram essa divisão de trabalho no grupo familiar.

[...] Mamãe cuidava de casa, de nós, da nossa comida, da nossa roupinha, que era pouquinha né. Ela cuidava disso aí. E nas horas vagas ela fazia bordado para vender em Fortaleza também. (Sr. A, 2001).

[...] Eu tinha que acordar cedo para tirar o leite das cabras, para fazer a comida dos perus, senão eles morriam, dá comida para os pintinhos, isso tudo era responsabilidade minha. (Sra. E, 2001).

O trabalho era realizado nas terras herdadas dos pais, ou em pedaços de terras compradas que, em geral, eram insuficientes para a produção de alimentos destinados a toda a família. Quando isso acontecia, o normal era que outro pedaço de terra fosse arrendado para ampliar os roçados. "[...] meu pai tinha uma roça, um terreno pequeno que a gente plantava milho e feijão, que era na parte dele, e o arroz nós plantava alugado, nós pagávamos a renda”. (Sr. C, 2001).

$\mathrm{O}$ excedente era vendido em feiras locais pelos próprios produtores, e com os recursos apurados com a venda do excedente da produção, eles adquiriam outros bens necessários para sua manutenção. As principais culturas plantadas nas roças de toco (áreas recém desmatadas sem ajuda de implementos agrícola) eram: mandioca, milho, arroz, feijão e abóbora. Lavouras estas denominadas pelos assentados, de subsistência, pois se destinam tanto ao autoconsumo, quanto à venda eventual.

A relação com o ciclo agrícola é muito importante, porque traz mudanças direcionadas às atividades cotidianas relacionadas com a terra. Segundo os entrevistados, em sua região de origem, no Nordeste, existem apenas duas estações: verão e inverno. Durante o inverno a atividade agrícola é maior, exigindo trabalho de toda a família. Todavia, no verão, o volume de atividades é substituído por outras compatíveis com a época. Garcia Jr. (1989) aborda a relação de dependência entre o 
calendário agrícola e as condições climáticas, principalmente as chuvas, sendo o planejamento das atividades afetado diretamente por essa relação.

E ainda, de acordo com os entrevistados, normalmente o pagamento dos trabalhadores temporários e contratados, que tinham a função de suprir as necessidades do trabalho no período de inverno, era feito através de produtos como rapadura, mandioca ou carne e não em dinheiro.

Já as crianças iniciavam o trabalho, na maioria dos casos, por volta dos sete anos. Muitas deixavam de estudar para ajudar os pais nas atividades da propriedade ou trabalhar para terceiros. Conforme explicação de um entrevistado, logo abaixo.

[...] eu comecei a estudar com nove anos, só que fiquei só três meses na escola, porque quem estudava era preguiçoso, era porque não queria trabalhar, e nós éramos muito pobre e precisava trabalhar para os outros para comer porque a gente não tinha terra, a gente morava numa currutela que a prefeitura tinha dado, então a gente trabalhava na terra dos outros (...). Eu trabalhava com cultura (milho, mamona, feijão andu e feijão de catar). (Sr. D, 2001).

Além da adversidade climática, o ideal de conquistar 'uma tripa de terra' ou 'um pedaço de chão' como condição de liberdade dos trabalhadores e camponeses, provocou a migração de grande contingente de pessoas das regiões Norte e Nordeste para o Sul.

[...]. Eu me lembro, que teve uma época, que teve uma seca muito grande lá [Umarizal-RN] em 1968. Foi muita seca. As coisas que o meu pai tinha, morreu tudo que o meu pai teve que ir embora, em 1968 para São Paulo, eu tinha 11 anos, para poder arrumar emprego, para mandar dinheiro pra gente melhorar a situação. O meu pai, quando foi embora para São Paulo para trabalhar de garçom, e mandava o dinheirinho todo o mês pra casa, foi isso que ajudou bastante. (Sra. E, 2001).

Portanto, as migrações para as regiões do Centro-Sul, como São Paulo, Rio de Janeiro, Belo Horizonte e Brasília, passou a ser uma alternativa para conseguir melhorar de vida ou até mesmo alcançar a sua liberdade.

Nessa perspectiva o estudo de Garcia Jr. (1989) sobre os camponeses do Brejo e Agreste da Paraíba, nos municípios de Areia e Remígio, ajuda a entender esse movimento migratório em alguns locais do nordeste. Nesta pesquisa o autor identificou um intenso processo de emigração desde o final dos anos 40, mostrando que as estratégias de articulação dos camponeses e da preservação de seus valores holistas são surpreendentemente criativas. Ou seja, os deslocamentos para as cidades industriais significavam, para os camponeses, uma forma de escapar da sujeição, o que passou a ser 
associado à noção de liberdade, porque, com o dinheiro obtido no Centro-Sul, eles podiam comprar terras para o cultivo. Não obstante, esses deslocamentos eram realizados por um verdadeiro sistema de recrutamento financiado pelos industriais do Sudeste, por meio da contratação de recrutadores que adotavam estratégias de dependência, tais como as utilizadas pelos Senhores de engenho. Sendo que aqueles que voltavam para a sua terra natal sempre procuravam "ocupar uma posição social mais alto que antes do deslocamento: o impensável seria voltar para ser morador" (GARCIA JR., 1989, p.77).

No entanto, a dominação tradicional não desapareceu, apesar de ter diminuído a eficácia das estratégias dos Senhores. Nas falas abaixo, essa situação pode ser evidenciada no trecho da entrevista sobre a decisão de migrar.

\footnotetext{
P: Como foi a ideia de vir para a cidade? Porque Brasília?

R: Nessas alturas uma irmã minha casou e, de 10 a 20 dias, o marido dela veio pra Brasília com o irmão dele, que trabalhava aqui em Brasília. Ele era funcionário público e tinha falado com o irmão que ia arrumar um emprego para ele também no ministério, que era o Ministério da Educação. Aí ele veio, e ele depois de um uns dois anos, ele mandou o dinheiro para que eu viesse morar com eles aí. Aí eu vim e não consegui serviço. (Sr. C, 2001)
}

P: Qual a ideia que o Sr. tinha de Brasília? Qual foi a reação dos seus pais, após a decisão de migrar?

R: Olha, eu pensava assim, eu vou para Brasília e vou ganhar dinheiro, e vou voltar e comprar um terreno para nós plantar. Aí o meu pai falou: o meu filho não vai não, ele fica aqui. Aí a minha mãe falou: não, deixa ele ir. Aí a minha finada avó chegou e falou com o meu pai: deixa ele ir, porque ele vai lá para o José. Lá ele não vai pagar aluguel, que o José falou. Aí ele junta o dinheiro lá e vocês compra um terreno, e depois vocês vão trabalhar melhor. Aí vocês vão poder até comprar outro barco para trabalhar melhor. Aí o meu pai colocou aquilo na cabeça. Aí eu vim. Só que quando eu cheguei aqui, ele não conseguiu me colocar. Aí eu tive que trabalhar numa obra. [Sr. C voltou três anos depois ao Maranhão e acabou levando para Brasília um irmão mais novo para trabalhar como ajudante de eletricista].

No trecho dessa entrevista é possível observar que a decisão do migrante de deixar o local de origem, sempre tinha o objetivo de arrumar emprego para comprar terra para a família. Sobre essa questão, Garcia Jr. (1989) mostra que muitos migrantes nordestinos deslocavam-se dos seus locais de origem com intuito de arrumar emprego nos estados do sudeste brasileiro visando juntar dinheiro para comprar terra.

As condições de vida difíceis que os entrevistados levavam em seus locais de origem e a própria atração que as cidades exerciam sobre eles foram fatores decisivos 
para que os entrevistados migrassem para Brasília, sobretudo entre as décadas de 70 e 80 do século XX.

\section{Brasília: cidade de encantos e desencantos}

Dentre os assentados entrevistados foi possível distinguir dois grupos de imigrantes que vieram para Brasília: o primeiro grupo foi aquele que veio de caminhão pau-de-arara antes dos anos 1970 para trabalhar na construção civil e, em alguns casos, participaram da construção de prédios públicos. Nesse período, esses imigrantes não tiveram dificuldades para encontrar empregos. Já, no segundo grupo estão aqueles que vieram depois dos anos 1970 e foram trabalhar, sobretudo, na prestação de serviços como, por exemplo, em oficinas mecânicas. A principal característica desse grupo está relacionada à conquista do emprego, graças aos parentes já instalados em Brasília. Os parentes e conterrâneos foram imprescindíveis para adaptação nesse novo habitat. Isso fez com que Brasília fosse escolhida por causa do apoio logístico que teriam na nova cidade.

De acordo com Durhan (1978), o apoio de parentes e amigos para os migrantes de origem rural é fundamental para a adaptação dos mesmos no meio urbano. Além dessa relação com parentes e amigos que estavam em Brasília, os entrevistados costumavam frequentar lugares como feiras regionais e mantinham algumas tradições como festas e comidas típicas, que era uma forma de manter viva a memória do lugar em que construíram suas identidades e onde deixaram suas raízes.

À volta ao local de origem, para visitar os parentes que ficaram, foi, na maioria das vezes, muito tempo depois de sua partida, isso acontecia devido à falta de dinheiro para a compra da passagem. Esse momento pode ser reafirmado com o depoimento abaixo do Sr. E (2001) e do Sr. B(2001):

Voltei lá 10 anos depois, em 1985. Eu voltei para ficar uns 15 dias para os meus filhos e marido conhecer o Nordeste. (Sra. E, 2001).

Depois de 25 anos foi que eu voltei a primeira vez. Cheguei lá como um estranho porque os meus irmãos que eu deixei lá solteiro estava tudo casado e pai de moças e rapazes $(\mathrm{Sr} . \mathrm{B}, 2001)$.

Além da falta de dinheiro, os migrantes encontraram outros desafios na cidade, $o$ mercado de trabalho era excludente, para aquelas pessoas que tinha baixo grau de 
escolarização e quem não tinha moradia própria em Brasília, o que os obrigavam a percorrer longas distâncias. Esta constatação reforça o que Cappellin (1990) observou a respeito de migrantes rurais. De acordo com a autora, os trabalhadores rurais que chegam às cidades vão trabalhar nas mais diversas atividades, porém, esses migrantes só conseguem se empregar na construção civil, atividade que não exige qualificação e não faz distinção entre trabalhador rural e trabalhador urbano. Contudo, nos últimos anos, foi ficando ainda mais difícil de arrumar emprego porque os trabalhadores tinham em média 50 anos de idade e baixo nível educacional, o que contribuiu para a sua exclusão do mercado de trabalho.

Para Montali (2000), as transformações do mercado de trabalho são decorrentes de um lado, da reestruturação produtiva, e de outro, da oscilação econômica das últimas décadas que repercutiu negativamente sobre o nível de emprego.

De modo geral, os sujeitos entrevistados no assentamento Vereda I, principalmente aqueles que moraram no Distrito Federal, viveram em casas construídas em terrenos urbanos 'dados' pelo governo do DF, nas cidades satélites: Ceilândia, Recanto das Emas e Samambaia. É importante explicar que a partir das entrevistas foi possível interpretar que o significado de 'terreno dado' demonstra uma relação característica entre governos do DF e população local, ou seja, o terreno dado tornavase dívida de gratidão do sujeito com o doador, mesmo que a pessoa que tenha ganhado o terreno pagasse por ele.

Borges (2003) aponta que essa expansão territorial e populacional no Distrito Federal acontece, sobretudo, pelos interesses de políticos que estimulam os migrantes a se fixarem no DF, em troca da transferência de seus títulos de eleitores para o DF. Desta forma, os terrenos se tornam um instrumento de barganha de votos.

De acordo com os entrevistados, as condições de vida no Distrito Federal sempre foram difíceis, pela falta de moradia, pelo aumento do desemprego e da violência. Logo, para os entrevistados, as condições em que viviam aliadas com a possibilidade de conseguir uma parcela de terra fizeram com que no ano de 1998, entrassem para o Movimento dos Trabalhadores Rurais Sem Terra (MST), buscando 'ganhar um pedaço de terra' por meio das ocupações de fazendas no Entorno do Distrito Federal.

\section{O assentamento e os ritos de passagem}


Ao analisar o grupo estudado no assentamento Vereda I buscou-se entender que a trajetória destes trabalhadores rurais migrantes foi marcada por diferentes fases que, no seu conjunto, formam o que Van Gennep (1960) apud Turner (1974), denomina de processo ritual, ou Ritos de Passagem que consistem em ritos que acompanham toda mudança de lugar, estado, posição social e de idade. Os Ritos de Passagem podem ser divididos em três fases, ou seja,

\begin{abstract}
Separação, margem (ou 'limen', significando 'limiar' em latim) e agregação. A primeira fase de separação abrange o comportamento simbólico que significa o afastamento do indivíduo ou de um grupo, que quer de um ponto fixo anterior na estrutura social, quer de um conjunto de condições culturais (um 'estado'), ou ainda ambos. Durante o período 'limiar' intermédio, as características do sujeito ritual (o 'transitante') são ambíguas; passa através de um domínio cultural que tem poucos, ou quase nenhum, dos atributos do passado ou de estado futuro. $\mathrm{Na}$ terceira fase (reagregação ou reincorporação), consuma-se a passagem (TURNER, 1974, p.116).
\end{abstract}

Tal explicação nos remete a perceber que no caso dos sujeitos pesquisados, a primeira fase do ritual de passagem na luta pela terra, corresponderia à fase de separação, ou seja, quando os trabalhadores resolvem participar das ocupações de terra, quando eles se vêem como sem-terras.

Destarte, no momento que o trabalhador resolve migrar para as áreas de conflitos de terras ele rompe com a estrutura social que o sustentava até então, e passa para uma nova fase, ou seja, para a segunda fase que é caracterizada pela liminaridade, neste caso o acampamento.

Nesse contexto o "movimento de luta pela terra é marcado pela emergência de uma série de ambigüidades, caracterizando uma situação de liminaridade" (MARQUES, 2000, p. 115), isto é, o processo de luta pela terra permite a experimentação do novo e o questionamento na prática, exaltando a capacidade crítica dos trabalhadores que participam de ocupações em relação a sua condição subalterna. Neste universo segundo a autora, o acampamento representa o espaço de resistência de natureza transitória, mas de duração indeterminada, em que se vive na expectativa de ser assentado na área reivindicada (MARQUES, 2000).

A fase de transição corresponde ao período que os entrevistados passaram a morar no acampamento e a se depararem com o desafio de um novo espaço social constituído. Outrossim, a liminaridade na luta pela terra pode ser considerada como um 
momento de reflexão, aprendizagem e um estado no qual esses sujeitos adotam uma nova postura política e social.

Sendo potencialmente um período de exame e questionamento dos valores e axiomas centrais da cultura em que ocorre Ela é um estado do social com grande capacidade de inovação, pois representa a possibilidade de livre recombinação dos fatores culturais nos mais variados padrões (MARQUES, 2000, p. 113).

A terceira fase do processo ritual, ou fase de incorporação ou de agregação começa com a criação do Projeto de Assentamento e a definição das famílias em suas chácaras $^{1}$. Nesse momento, o trabalhador deixa de ser sem-terra para se tornar assentado, iniciando uma nova organização social. Desta maneira os assentamentos tornam-se lugar para construção de novos elementos e de outros rearranjos sociais.

Nesse sentido, como diria Carvalho (1999) o assentamento passa a ser uma encruzilhada social, onde há novas formas de socialização e novos saberes serão adquiridos, além disso, muito dos saberes que foram acumulados ao longo de suas trajetórias de vida, geralmente, são reproduzidos neste ambiente. A partir desse momento, passam a se encontrar face a face nesse espaço físico, social, político, ambiental e econômico que irão reproduzir seus novos meios de vida e de trabalho.

\section{O sonho da terra}

Como foi dito anteriormente no município de Padre Bernardo o marco de luta pela terra foi o ano de 1998, quando militantes do MST que atuavam no Distrito Federal vinham realizando um trabalho de base junto a moradores, nas periferias das cidades satélites de Brasília, convidando para que esses viessem a ocupar terras na região. Além disso, os assentados que foram para região acabaram sabendo das ocupações através das redes de amizades e parentesco ali existentes. Nesses espaços, essas redes tendem a ser mais fortes e por isso podem ser vistas como bases importantes para a mobilização desses trabalhadores.

Esse tipo de estratégia de mobilização por parte do MST, na região do Entorno do Distrito Federal, também foi observada por autores como Sigaud (2005) em outras regiões do país como em áreas de acampamentos na Zona da Mata Sul do Estado de

\footnotetext{
${ }^{1}$ Segundo os assentados, 'chácara' é uma parcela de terra maior que um lote e menor que uma fazenda, onde cada família ocupa a extensão total de 20 hectares, incluindo a moradia e a área de terra para plantio.
} 
Pernambuco. Assim, em Pernambuco muitos dos trabalhadores que foram participar da luta por terra, passaram a viver nos acampamentos, e o foram a partir de convites feitos por militantes do MST e sindicalistas nas periferias das cidades da Zona da Mata pernambucana.

Em relação aos sujeitos que foram participar dessas ocupações em sua maioria eram desempregados, trabalhadores com idade avançada, com pouca escolaridade e que não tinha nenhuma experiência em organizações sociais ou em militância, por consequência, pouco conhecimento sobre o MST. As informações que eles tinham eram aquelas transmitida pela imprensa televisiva, especialmente, através do acontecimento de Eldorado dos Carajás, em 1996. Conforme pode ser observado na fala abaixo,

Rapaz, eu tinha um medo daquilo [das ocupações]. Medo demais, porque a gente via as brigas, principalmente naquele lugar que teve as mortes, no Pará, em Eldorado, onde matou um mucado de gente lá. Então aquilo ali me deixou como medo.(Sr. G, 2001).

No movimento eu ouvi falar, naquela ocasião, que teve aquela briga lá no Pará, onde mataram o Chico Mendes, era negócio dos sem-terras. E eu ficava pensando, será que eu vou para os sem-terras, será que vai acontecer comigo desse jeito também? (Sr. D, 2001).

A decisão de ir para o acampamento foi tomada depois de conversarem com os parentes. Mesmo sabendo que alguns seriam contrários a essa decisão, eles resolveram partir por acreditar 'no sonho da terra', e muitos foram acompanhados de vizinhos ou parentes que já estavam no movimento há mais tempo. De acordo com Carvalho (1999), o trabalhador sem-terra pode ser caracterizado como um 'nômade geográfico e social' pela sua mobilidade social e pelas suas estratégias de sobrevivência. Para o autor, as pessoas que migram para áreas de ocupações de terras saem de seu local de origem em grupo ou em famílias, e o fazem, frequentemente, com algum respaldo ou apoio logístico de amigos, vizinhos ou parentes que continuaram em seus locais de origem.

As famílias que ocuparam a área da antiga fazenda denominada Serra Feia se organizaram em acampamento, inicialmente, em fevereiro de 1999, sob coordenação do MST. O acampamento foi montado na divisa das fazendas Serra Feia e Buriti da Espingarda no município de Padre Bernardo, Goiás, na beira do rio Quente, local escolhido por causa do acesso fácil à água e pela proximidade com a fazenda Buriti, que faria parte do assentamento Boa Vista. O local era estratégico, pois facilitaria uma fuga rápida em caso de necessidade. Neste local, foi construído um galpão comunitário, onde 
eram preparadas e realizadas as refeições, até que todas as famílias construíssem seus 'barracos'. Destarte, as famílias ficaram neste local aguardando as negociações entre o proprietário e o INCRA.

De acordo com os entrevistados, a rotina no acampamento se dividia entre reuniões e trabalhos coletivos como plantar, cozinhar, tirar guarda ${ }^{2}$ e, nos finais de semana, aconteciam bingos ou festas nos acampamentos das fazendas vizinhas, cujo objetivo era arrecadar dinheiro para a manutenção dos acampamentos.

Em novembro de 1999, os acampados resolveram romper com as lideranças do MST, porque os mesmos, segundo os assentados, estavam negociando lotes e na visão deles essas lideranças estavam faltando com a verdade para com os acampados. Reunidos em assembleia, no dia dois de novembro de 1999, decidiram romper definitivamente com os líderes locais do MST. Esse momento, segundo os assentados, retratou as diferenças existentes entre o grupo de acampados e as lideranças do MST, fazendo com que as famílias que continuaram acampadas passassem a ser organizadas por um grupo de acampados, escolhidos em assembleia. Nesse sentido, foi possível especular que os interesses das lideranças se chocou com a visão de mundo do grupo, o que acabou provocando o rompimento dos acampados com o movimento.

É importante ressaltar que sobre o rompimento com o MST, não foi possível entrevistar as lideranças que haviam organizado a ocupação no município, pois os mesmos já não mais se encontravam na região e aqueles assentados que ainda nutriam algum respeito pelo movimento, não gostavam de conversar sobre o assunto, pois segundo eles tinham sido um momento muito tenso na fase de acampamento e cheio de ressentimentos com as lideranças que representavam o MST que haviam sido expulsas.

Após o rompimento com as lideranças do movimento, o passo seguinte foi 'cortar a fazenda na corda', ou seja, parcelar a fazenda entre os acampados para que a mesma fosse totalmente ocupada pelas famílias que moravam no acampamento, evitando, dessa forma, a possível volta do MST.

Destaca-se que a medição na corda foi realizada com ajuda de um arame liso de pouco mais de 50 metros e um esquadro de $4 \times 3$ metros, assim os assentados demarcaram toda a fazenda em lotes de 1.000 metros de lateral com 200 metros de

\footnotetext{
${ }^{2}$ Tirar guarda, se refere aqueles assentados que ficavam responsável pela segurança do acampamento e pelo controle da entrada e saída de visitantes, assim, eles cumpriam um papel na organização do acampamento evitando inclusive a presença de estranhos e possíveis furtos.
} 
fundos, totalizando 20 hectares para cada família, num total de 70 chácaras. O assentado, que ficou responsável pela medição do assentamento havia trabalhado por muitos anos como pedreiro na empresa de construção Andrade Gutierrez.

O trabalho foi coordenado pelos próprios acampados e levou onze dias para ser realizado, com média de cinco a seis pessoas que se revezavam na abertura dos caminhos para a demarcação da área. Destaca-se que apenas o coordenador da medição foi quem acompanhou o trabalho desde o início. As mulheres, também, tiveram um papel importante nessa demarcação, pois eram elas que cozinhavam e levavam a comida ao local onde estava sendo realizado o trabalho. No dia 16 de janeiro de 2000, depois da realização da medição da fazenda na corda, os acampados realizaram o sorteio das chácaras, com objetivo de definir a área a ser ocupada pelas famílias. No final do ano 2000, os técnicos do INCRA realizaram o parcelamento oficial do assentamento, e em janeiro de 2001, durante a realização do Plano de Desenvolvimento de Assentamento (PDA) que os assentados tiveram suas parcelas homologadas. Destaca-se que os técnicos do INCRA na medida do possível respeitaram a medição inicial dos assentados, entretanto, foi necessário realocar cerca de 20 famílias que na medição dos assentados tinham sido colocadas em áreas consideradas de reserva legal. Esse remanejamento foi discutido com os assentados durante o processo de elaboração do PDA.

O nome do assentamento ficou definido como Vereda I, pelo INCRA. No entanto, de acordo com os assentados, o INCRA não respeitou a vontade dos mesmos quanto à escolha do nome. Eles gostariam que o assentamento fosse chamado de $25 \mathrm{de}$ julho, data da entrada definitiva na terra e, também, dia comemorativo do trabalhador rural. Atualmente, se consideram assentados da fazenda Serra Feia e não Vereda I, segundo eles, é apenas um nome que serve para tratar com o INCRA.

Conforme os assentados disseram nas entrevistas, os meses que antecederam a assinatura dos contratos foram de muita luta. Contudo, após assinarem os contratos eles tiveram a certeza que ficariam naquele local.

Foi debaixo de muita pressão que o INCRA entregou os contratos. Foi preciso a gente filmar todo o assentamento e baixar na porta do INCRA com mais de 50 famílias e ameaçar o pessoal que nós íamos levar a fita no 'Ratinho'[programa de televisão]. Foi que o superintendente apareceu e assumiu o compromisso com a gente, mais só acreditamos quando foi feita uma ata de compromisso e assinada pelo Sr. Manuel, superintendente do INCRA (Sr. Ar, 2001). 
É importante ressaltar que em julho de 2001 os assentados assinaram o contrato com o INCRA e começaram a receber o crédito instalação, ou antigo crédito apoio. Em 2001 o valor do crédito instalação era de $\mathrm{R} \$ 1.400,00$ (um mil e quatrocentos reais) sendo $\mathrm{R}$ \$ 400,00 (quatrocentos reais) destinados à compra de gêneros alimentícios e R \$ $1.000,00$ (um mil reais) para a compra de ferramentas ou para o pagamento de horas de trator para o plantio.

Nesse período o assentamento foi constituído por famílias vindas de vários estados da federação, com destaque para os estados da região Nordeste, que totalizam $40 \%$ de nordestinos morando no assentamento. Dentre os estados da região Nordeste, o Maranhão se destaca com 12,86\%. Mas ressalta-se que $90 \%$ dos assentados tinham como domicílio anterior ao assentamento, alguma cidade satélite de Brasília. Além disso, outra característica importante do grupo do Vereda I é que $82,86 \%$ têm origem rural, mas viveram na cidade por um período médio de 15 anos, antes de migrarem para o assentamento.

\section{A organização social do trabalho e a produção no assentamento}

Durante a pesquisa levantou-se que nos primeiros anos da criação do assentamento a produção concentrou, com as necessidades alimentares que visavam assegurar a alimentação direta e imediata da família, ou seja, as famílias priorizaram as culturas como: milho, feijão, arroz, abóbora e mandioca. Segundo eles essas culturas não exigiam tanto recursos, além de garantir a alimentação das famílias. Em média, nos primeiros anos os assentados plantaram cerca de dois hectares por família, variando de acordo com o tamanho da família e as condições financeiras destas, sendo esta a situação mais preponderante. Sobre o restante da parcela, os assentados dividiram entre pastagem, reserva legal (cinco hectares), e áreas para a construção da casa, galinheiros e currais. Ainda sobre o cultivo quando havia excedente de produção este era levado para ser vendido, na cidade satélite da Ceilândia, local onde os assentados pegavam as conduções para o assentamento.

Posteriormente em 2003, com a saída dos créditos do Programa Nacional de Fortalecimento da Agricultura Familiar (PRONAF), a produção foi, aos poucos, sendo diversificada, sendo introduzida, gado misto e caprinocultura, e as áreas de plantio de 
mandioca e milho foram ampliadas. Entretanto, na última visita a campo em setembro de 2006 os assentados reclamaram que a falta de assistência técnica e a falta de vivência para trabalhar com as criações e até mesmo nas terras do cerrados, tinham levado os mesmo a uma dívida (créditos) que eles não sabiam como iriam pagar.

Sobre a relação do ciclo agrícola e o trabalho feminino, as mulheres entrevistadas explicaram que nos períodos de chuva, quando se tem maior disponibilidade de água para produzir, o trabalho das mulheres é mais intenso na roça. Além disso, é o período ideal para se realizarem mais tarefas. É importante ressaltar que em algumas chácaras, é a mulher que é a proprietária e todo o trabalho é realizado por ela com ajuda de filhos ou até mesmo através da utilização de algum mecanismo de ajuda mútua. "Aqui, eu trabalho quase que sozinha, quando eu preciso de um serviço mais pesado eu pago um dia de serviço para o fulano ou eu entro no mutirão" (Sra. AI, 2004).

Autores como Giacobbo (1994) mencionam que a participação da mulher na roça depende de vários fatores, entre eles, o ciclo de vida familiar, idade, número e sexo dos filhos, a possibilidade ou não de contratar mão de obra, dentre outros. Dessa forma, o trabalho da mulher não fica restrito apenas ao serviço doméstico.

A mulher trabalha juntamente com o homem na 'roça', desempenhando tarefas muitas vezes específicas do processo produtivo. Mas sua participação nessas atividades é vista como 'ajuda. (GIACOBBO 1994, p85).

Na rotina diária das mulheres, foi possível observar que no período de chuvas se exige maior dedicação nas lavouras, isso porque segundo elas o período do verão é muito quente e não teria muitas atividades para fazer nas chácaras, assim, nessa época os assentados vão buscar trabalho na cidade.

Sobre o trabalho em grupo, alguns assentados têm o hábito de trocar dias com seus vizinhos ou amigos, reforçando laços de vizinhanças, que são essenciais no desenvolvimento do trabalho. "A troca de dia é o seguinte: um vizinho ou parente vem para mim e trabalha na minha roça hoje, e depois eu fico devendo o dia para ele, ai eu vou e trabalho na roça dele depois é assim, sem dinheiro só é pago com o trabalho" (Sr. B, 2006).

Assim, a relação de vizinhança, segundo Lima Jr. (1988), é uma relação social considerada essencial para os camponeses, porque os vizinhos participam de diversas atividades como troca de bens e troca de dias. Em alguns casos, para a realização da 
troca de dias, o critério adotado é o desempenho do parceiro nas atividades relacionadas com o trabalho a ser desenvolvido.

Desta forma, alguns grupos foram se formando no assentamento para plantar arroz e constituir uma casa de farinha. Para formação do grupo, todos os assentados foram convidados, no entanto, a participação no início foi pequena, mas com o tempo chegou a 20 famílias, em sua maioria daquelas famílias que ficam direto no assentamento. Outra característica desse grupo é que em sua maioria os participantes são mulheres.

Para Bauman (2003), esse tipo de contrato que se estabelece numa comunidade é centrado na ideia de ajudar uns aos outros para, quando precisar, obter a ajuda necessária.

Esse tipo de solidariedade é vista também em outras ocasiões, como no caso da construção do templo da Igreja Missão de Cristo Mundial, que foi construída com dinheiro de doações de membros da cidade, pois a sua principal sede fica na Ceilândia, cidade satélite do DF. Mas a construção foi realizada em regime de mutirão. Segundo um dos pastores, responsável pela igreja, ela levou 60 dias para que ficasse pronta. Para ele, o mutirão simbolizava a participação de todos e o envolvimento e a fé daqueles que acreditam na obra de Deus. "Se um pastor falar que vai construir com o dinheiro dele, não é legal porque tem que ter a participação de toda a comunidade" (Sr A, 2006).

Outrossim, existem assentados que precisam exercer trabalhos temporários na cidade, sobretudo, nas cidades satélites de Brasília. Esses trabalhos estão diretamente relacionados com as atividades que os entrevistados desempenhavam no período que residiram na cidade, tais como: trabalhos com frete, servente de pedreiro, carpinteiro, mecânico, furador de cisternas, dentre outros.

[...] Eu não estou indo muito para a cidade mais não. Tenho ido pouco, só quando precisa de alguma coisa que eu vou. Passo uns dois dias lá, faço um frete, compro um açúcar, uma carninha e volto porque a minha vida é aqui mesmo (Sr. B, 2001).

Essa estratégia de procurar trabalho na cidade, segundo os entrevistados, é mais vantajosa do que o trabalho temporário realizado para fazendeiros da região, porque, quando eles conseguem esses alternativos na cidade, a remuneração é maior do que na zona rural. Porém, o principal problema é conseguir esses trabalhos temporários e ter que deixar a propriedade por conta de outros membros familiares. 
Observou-se no assentamento que alguns familiares se encontravam na casa dos parentes aguardando a oportunidade de conseguir um lote. Essa relação é conhecida pelos assentados como 'encostados', ou seja, na visão dos assentados esses parentes ficam em suas casas até conseguirem um pedaço de terra ou então desistirem e voltarem para seu local de origem, como pode ser observado na fala "Eu trouxe do Maranhão o meu pai e a minha irmã aqui para Goiás para ver se eles conseguem ganhar terras, também, porque lá as coisas eram muito difíceis para eles" (Sr. I, 2004). Em conversa com o pai deste assentado o mesmo relatou que essa ajuda do filho foi muito importante para que ele pudesse conseguir um suporte até se ajeitar na região, pois, com a idade avançada, as coisas seriam mais difíceis e sem essa ajuda provavelmente não teria conseguido ficar na região.

Outros autores como Lima Jr. (1988), também, observaram situações semelhantes em outras regiões do país, em que o 'encostado' ${ }^{3}$ é aquele sujeito que fica no lote de um parente em uma condição provisória, até arrumar um lugar ou uma terra para ficar. Neste caso, a pessoa que oferece o 'encosto' acaba contribuindo com apoio logístico.

\section{Perspectivas com o assentamento}

Durante os trabalhos de campo e a convivência com os assentados, foi possível observar que as famílias mantêm uma forte relação com a terra, mesmo depois de muitos anos vivendo em Brasília, trouxe aos migrantes experiências novas que os fizeram refletir sobre as experiências passadas. Assim, a memória de um passado camponês foi reativada para reproduzir aspectos culturais valorizados por eles, mesclados com os valores culturais adquiridos na cidade. O próprio nome que é dado à parcela - pedaço de terra - que eles recebem está relacionado com essa mesclagem. Ou seja, normalmente, no seu local de origem, os entrevistados denominavam a terra em que moravam de sítio. No assentamento, a parcela é denominada chácara, uma alusão clara aos valores culturais de Brasília. Essa influência se deve ao fato de muitos terem

\footnotetext{
3 "Camponeses encostados, termo que designa o filho, irmão, casado com a irmã ou genro do dono (proprietário ou posseiro) do lote em que fixa a residência. Uma das suas características é sua provisoriedade e exclusão. Quem se encosta não pode permanecer encostado indefinitivamente. Caso se encoste no pai, não deverá herdar aquele lote" (LIMA JR, 1988, p.49).
} 
trabalhado, por algum tempo, como chacareiros ou tomadores de conta de pequenas porções de terra no Entorno do Distrito Federal.

Assim, após a conquista da terra, os assentados deparam-se com um novo desafio que passa a ser construído coletivamente e também individualmente. Vai desde o fortalecimento da sua organização através de sua associação, do desafio de viverem num modelo de agrupamento diferente ao que estavam acostumados e de até mesmo da obtenção de infraestrutura necessária para a sobrevivência deles.

Nesse novo espaço diversos mecanismos são acionados, isto é , vão desde o controle social através da fofoca ou da vergonha e passam pelas condições climáticas como, por exemplo, o ano agrícola é determinado pelo ciclo chuvoso, que se inicia no final de setembro com as chamadas chuvas do cajueiro, que determina o início do processo produtivo no assentamento.

Sobre o processo produtivo nas narrativas apresentadas pelos assentados, percebe-se que eles tiveram dificuldades para exercer a nova condição de assentados. Isso porque, apesar de terem vivido uma parte de suas vidas em contato com a terra, a maioria nunca tinha estado à frente de algum estabelecimento de produção. Os assentados expressaram que tinham uma experiência muito grande, mas com outras atividades como pedreiro, carpinteiro, motoristas, diarista, empregadas domésticas, caseiros, entre outros. A experiência com a roça estava limitada ao período que passaram morando com os pais na infância ou adolescência, sobretudo em regiões dos estados do nordeste brasileiro.

Essa situação fez com que a maioria tivesse problemas para administrar sua chácara, especialmente, no que tange à aplicação dos recursos como os créditos do PRONAF, além da falta de conhecimento de como lidar com as terras do cerrado. Outra constatação é que mesmo anos depois de criação do assentamento, a água continuava sendo um dos principais desafios que as famílias encontram, não só para o consumo, como também para a produção, pois a falta desta inviabiliza o cultivo de muitas culturas. A energia elétrica só chegou ao final de 2005 e início de 2006, mesmo assim através do projeto Luz Para Todos, uma parceria do Governo Federal com a concessionária de energia do Estado de Goiás.

Outro fator agravante é o baixo nível tecnológico que o assentamento se encontra, com poucos recursos, ausência de assistência técnica e com grande parte de 
seus moradores endividados. As condições de produção ficam comprometidas, o que tem contribuído para a rotatividade na região.

Sobre essa questão autores como Leite et al. (2004), apontaram que a ausência de créditos, assistência técnica e infraestrutura têm contribuído de forma significativa para impossibilidade das condições produtivas dos assentamentos rurais no Brasil.

No entanto, com ações de parceria de mediadores, sobretudo das universidades (UnB e PUC de Brasília), esses assentados têm buscado alternativas de sobrevivência através de ações coletivas e até mesmo individuais, o que tem contribuído para melhorar a vida desses sujeitos no assentamento.

Além disso, a permanência dos assentados nesse espaço vai depender de que o Estado crie uma série de condições (infraestruturas, créditos, assistência técnica de qualidade, dentre outras) que permitam que as pessoas de fato possam escolher ficar na terra.

\section{Considerações finais}

Propusemo-nos neste artigo analisar as razões que levaram trabalhadores rurais a migrarem do campo para as cidades, e depois para o assentamento Vereda I município de Padre Bernardo, Goiás, região do Entorno do DF, focalizando a organização social resultante desse processo. Outrossim, procuramos analisar a migração em um contexto que migrar para os sujeitos estava relacionada com a possibilidade de mudanças quanto às condições de vida em diferentes fases das vidas dos entrevistados. No momento em que decidiram migrar do campo para a cidade tinham a esperança de melhorar de vida, procuravam sair das condições de precariedade em que viviam, seguindo rotas de parentes que os antecederam, mostrando assim, uma relação entre migração e rede de parentesco.

Na cidade, o sonho não se concretizou, sobretudo pelas mudanças que ocorreram no mercado de trabalho nas últimas décadas, em relação, à especialização. Isso fez com que os migrantes entrassem na luta pela terra na busca no assentamento um local para viver e trabalhar.

Ademais, observamos que as trajetórias dos assentados são motivadas pela esperança de, algum dia, melhorar de vida. As decisões de migrar do campo para a cidade e, depois, para o assentamento estão relacionadas com as condições de trabalho e 
com a possibilidade de inclusão como membro de uma comunidade, seguindo rotas de parentes que os antecederam, mostrando assim, uma relação entre migração, parentesco e ressocialização. Neste sentido, as condições estruturais nas áreas de assentamentos rurais favorecem a ressocialização dos trabalhadores, pois se encontraram em situação e em contexto social muito semelhante, fazendo com que recorram às antigas tradições culturais, dentre as quais o saber camponês, como segurança de que irão sobreviver.

Assim, migrar para uma área de ocupação de terras poderá significar a possibilidade de agregação, nesse espaço, de laços de parentesco que estavam dispersos. Desta forma, podemos inferir que o assentamento pode ser um momento de novas configurações familiares, além de ser um espaço de experiências políticas e culturais, no qual passam a se construir novas redes de relações sociais que se dão através da convivência com pessoas de várias origens. Destarte, a vida cotidiana é formada por laços de solidariedade com referência na tradição, no parentesco e na ajuda mútua.

Por fim, entendemos que os assentados se igualam na luta pela terra e por melhores condições de vida, por outro, eles possuem características heterogêneas forjadas nas trajetórias de vida que cada um passou individualmente, desde o momento da desagregação em seus locais de origem até os assentamentos. Outrossim, entendemos que a luta pela terra consiste num processo ritual de trajetórias singulares, explorando os diversos tipos de entrelaçamentos emergentes nas respectivas fases, que correspondem às trajetórias de vida das famílias assentadas, tornam-se de grande relevância para compreendermos a organização social dos assentados e para elaboração de políticas públicas adequadas à realidade destes tipos de assentamentos.

\section{Referências bibliográficas}

AGUIAR, Tereza Coni; MAGUAGO, Angélica Alves; BARRUCHO, Roberto de Castro Nóbrega; et al. O Entorno do Distrito Federal: no espaço e desordem ambiental. In: Anais do IX Encontro, 1994, v.2. pp.131-141. Disponível em: 〈www.abep.org.br〉 Acesso em out./2001.

BAUMAN, Zygmunt. Comunidade: a busca por segurança no mundo atual. Rio de Janeiro: Jorge Zahar. 2003. 141p.

BORGES, Antonádia. Tempo de Brasília: Etnografando lugares-eventos da política. Rio de Janeiro, Relumé Dumará-NUAP/UFRJ. 2003. 194p. 
BRASIL, INSTITUTO NACIONAL DE COLONIZAÇÃO E REFORMA AGRÁRIA. Resolução ño. 138, 22 de dezembro de 1997. Dispõe sobre a criação da Superintendência Regional do Distrito Federal e Entorno-SR(28), com jurisdição abrangendo as áreas de atuação do Distrito Federal e municípios do Entorno. Diário Oficial [da República Federativa do Brasil], Brasília, n.52, p.30863, 23 dez. 1997. Seção 1.

CAPPELlin, Paola. A lembrança do Sul. In: Travessia, ano 3 nº 8, set-dez de 1990. pp.13-17.

CARVALHO, Horácio Martins. A interação social e as possibilidades de coesão e de identidade social no cotidiano da vida social dos trabalhadores rurais nas áreas oficiais de reforma agrária no Brasil. MPF-NEAD-IICA. Curitiba. 1999. 70p.

DURHAN, Eunice. A caminho da cidade. São Paulo: Perspectiva S.A., 1978. $3^{0}$ parte, pp.95-141.

GARCIA JÚNIOR, Afrânio Raul. O Sul: caminho do roçado - estratégias de reprodução camponesa e transformação social. São Paulo/Brasília: Marco Zero/EdUnB. 1989. 285p.

LEITE, Sérgio; MEDEIROS, Leonilde, PALMEIRAS, Moacir. et al. Impactos dos assentamentos: um estudo sobre o meio rural brasileiro. São Paulo, Editora da UNESP. 2004. 392p.

LIMA JÚNIOR, Aurélio Viana. Dos pressupostos da ação política do campesinato: o caso da "invasão" da Fazenda Annoni. Rio de Janeiro, RJ: Universidade Federal do Rio de Janeiro, (Dissertação - Mestrado em Antropologia). 1988. 146p.

MARQUES, Marta Inez Medeiros De sem-terra a "posseiro", a luta pela terra e a construção do território camponês no espaço da reforma agrária: o caso dos assentados nas fazendas Retiro e Velha - GO. São Paulo, SP: USP, 2000. (Tese em Geografia Humana).

MONTALI, Lilia. Família e trabalho na reestruturação produtiva: ausência de políticas de emprego e deterioração das condições de vida. Revista Brasileira de Ciências Sociais, 2000. vol. $15 \mathrm{n}^{\circ}$. 42. pp 55-71.

OLIVEIRA, Marcelo Leles Romarco de Oliveira. Trajetórias de migrantes para Brasília e assentamentos rurais: $O$ caso do Vereda I. Viçosa, MG: Universidade Federal de Viçosa, (dissertação de mestrado em Extensão Rural). 2002. 136p.

SIGAUD, Ligia. As Condições de possibilidade das ocupações de terra. In: Tempo Social. vol.17, nº 1, USP, São Paulo, Jun 2005, pp. 255-280.

STEDILE, João Pedro e GORGEN, Frei Sergio. A luta pela terra no Brasil. São Paulo: Página Aberta, 1993. 117 p. 
TURNER, Victor W. O processo ritual: estrutura e antiestrutura. Tradução CASTRO, Nancy Campi. Petrópolis, Vozes, 1974. pp 116-159.

WOORTMANN, Ellen F.; WOORTMANN, Klaas. O trabalho da terra: a lógica e a simbólica da lavoura camponesa. Brasília, Editora UnB, 1997. 192p

Recebido para publicação em junho de 2011 Aprovado para publicação em junho de 2012 